\title{
Towards a Quality Agenda for Family Medicine
}

\author{
Warren P. Newton, MD, MPH, Elizabeth Baxley, MD, Michael K. Magill, MD, \\ Bob Phillips, MD, MSPH, and John Brady, MD
}

( J Am Board Fam Med 2021;34:455-457.)

The American Board of Medical Specialties (ABMS) has developed new draft Standards for Continuing Certification, which will be released for public comment in spring 2021. These new standards call on member boards to develop a quality agenda for their specialties, working closely with their specialty societies and other partners. On December 11, 2020, ABMS hosted a national symposium on this issue, with 21 of 23 boards and more than 112 specialty societies and clinical systems participating.

Why do we need a national agenda for improving quality of care for family medicine? The answer seems clear. As the National Research Council has found, we are sicker and die earlier than people in comparable countries, and the gap is growing. ${ }^{1}$ Furthermore, despite the implementation of the Affordable Care Act and 15 years of tech-driven transformation, US life expectancy has begun to drop, ${ }^{2}$ and COVID-19 has laid bare, once again, disparities of health and health care across race, ethnicity, and socioeconomic status. Finally, 2 decades since the publication of Crossing the Quality Chasm $^{3}$ and the RAND ${ }^{4}$ study that demonstrated that only about $50 \%$ of Americans were receiving guideline-based care across the continuum of care, the United States has fallen short of delivering consistently safe, high-quality care. ${ }^{5-7}$

As the largest and most widely distributed group of personal physicians, family physicians have the opportunity to be engaged in improving care delivery and outcomes across the continuum of care; in many

From the American Board of Family Medicine, University of North Carolina School of Medicine, Department of Family Medicine, Chapel Hill (WPN); American Board of Family Medicine, Lexington, KY (EB, BP, JB); American Board of Family Medicine, University of Utah School of Medicine, Department of Family and Preventive Medicine, Salt Lake City (MKM).

Conflict of interest: Dr. Newton is the President and Chief Executive Officer of the American Board of Family Medicine.

Corresponding author: Warren P. Newton, MD, MPH, American Board of Family Medicine, 1648 McGrathiana Pkwy, Suite 550, Lexington, KY 40511 (E-mail: wnewton@ theabfm.org). cases, family physicians are already leading this process. The Quadruple Aim ${ }^{8}$ is an appropriate targetand our commitment to address this comes out of our common sense of professionalism and responsibilities defined by the social contract. This is important to do at a specialty level. ${ }^{9}$

How do we set an "agenda for quality of care in family medicine," and who should be involved? In advance of the symposium, the American Board of Family Medicine (ABFM) reached out to the American Academy of Family Physicians (AAFP), who agreed to help lead this effort. We are now seeking to engage the "family of family medicine"-all clinical and academic organization-as well as a broad swath of practicing physicians, both independent and employed, along with employers, health systems, payers, patients, and the public. We envision a process similar to the development of the national quality strategy that serves as the model for this work, with convening of a diverse and representative group, development of a draft plan, and iterative involvement of our specialty to come to a final agenda for the specialty. While the pandemic, vaccine distribution, payment reform, and health equity are urgent challenges now, the development of a broad quality agenda will be critical for reshaping the clinical landscape after COVID-19. ${ }^{10}$

A second consideration is to understand our starting point. Family medicine has demonstrated commitment to performance improvement from the beginning of the specialty. ABFM, the first specialty board to require recertification, included chart audits as a part of recertification-in other words, performance in addition to knowledge. Evaluation of our quality is inherent to who we are. In the words of Goethe, "Knowing is not enough; we must apply. Willing is not enough; we must do." 11

Currently, on average, more than 30,000 family physicians complete ABFM performance improvement (PI) activities each year. Originally inspired 
by the seminal Institute of Medicine (IOM) report Crossing the Quality Chasm, ${ }^{3}$ and organized by the most important clinical conditions identified by the IOM, these activities have been developed by the ABFM with external partners, including the AAFP, which also provides continuing medical education (CME) credit for many of the PI activities. In 2017, ABFM developed a self-directed PI activity, which allows flexibility of focus and significantly reduces burden for Diplomates by allowing reporting on quality improvement efforts already being done. We also developed the PRIME registry, which allows easy extraction of data to drive and report quality improvement.

Starting in mid-2019, the ABFM PI team has developed and added 15 new activities to address care delivery in a variety of settings and scope in which family physicians practice. $98 \%$ of Diplomates report that these activities are relevant to family medicine, 95\% report relevance to their own practice, and $85 \%$ indicate that the intervention they implemented resulted in changes in care processes or outcomes. In parallel, there has been expansion of ABFM's organizational PI activities sponsored by accountable care organizations, health systems, large practices, and other organizations to further align improvements in care at the system or population level, while further reducing the barrier to reporting for individual Diplomates.

So, what should the family medicine agenda for quality be going forward? We recognize that many quality measures derive from a reductionist, diseaseoriented model that, while useful, may fail to capture the full power of family physicians in communities. $\mathrm{ABFM}$ and the AAFP believe that a first priority should be the development, approval, and spread of quality measures that better capture what family physicians do and its corresponding value. To this end, we developed the PRIME registry to develop and test new measures ${ }^{12}$ and are now focused on developing measures of continuity, low-value care, comprehensiveness, and a patient-centered care outcome measure. ${ }^{13} \mathrm{We}$ and others have also developed tools to assess and address social drivers of health. After initial development and testing, followed by a lengthy process of measure approval, implementation by insurers can occur. We appreciate the AAFP's support in advocacy and welcome partner health systems and insurers for testing these measures in large populations.

A second priority is education in performance improvement for residents and Diplomates. Education about how to improve care in practice is not effectively accomplished by a single PowerPoint presentation; it is a learn-by-doing process that needs mentoring, feedback, and experience with a variety of methods to bring about change. At the Accreditation Council for Graduate Medical Education level, although systemsbased requirement has been a general requirement for almost 20 years, the Family Medicine Review Committee made education in performance improvement a focused requirement in 2014. With approximately 4500 residents graduating per year, roughly one quarter of family physicians now have training and some direct experience improving care in practice. Thus, the large majority of family physicians have likely not had foundational education in health system science and quality improvement. It falls to the AAFP, the Institute for Healthcare Improvement, and other CME providers as well as health systems, state medical societies, and others to provide this education. Moreover, given the breadth of family medicine, we need to consider how to improve care wherever family physicians practice across the continuum of carefrom their care in our continuity practices, to emergency departments and the hospital, labor and delivery, and nursing homes. We must also support activities in patients' homes and neighborhoods and those that address improvement of community services critical to health equity. How to do this well, in a way that supports a meaningful role by physicians, and at scale, but in a way that does not feel like a check box activity, is a critical issue for the discipline.

A third priority is to improve performance improvement itself. Critical to this are timeliness and the right balance of rigor and burden-enough rigor to be meaningful but not so much to weigh down the process. In this context, the success of ABFM's COVID-19 PI activity introduced on April 1, 2020 is instructive, with more than 7000 family physicians as of this writing reporting on practice changes they made in response to the pandemic. Our hope is that our new health equity PI activity will also support family physicians engaging in a wide variety of activities to address social determinants and improve health equity. The ABMS also recommends extension of PI to community interventions, including those around social determinants, as well as to other roles that physicians serve-as educators, executives, and researchers, using a similar plan-do-study-act approach. PI needs to be built into all we do.

Family medicine can also learn from other boards and specialties. The ABMS Task Force on Improving 
Health and Health Care is developing a list of best practices to assist all certifying boards to create meaningful activities to drive the improvement of care. A good first place to look is the American Board of Pediatrics, which has led the boards in identifying and developing networks for quality improvement, with demonstration of dramatic improvement in outcomes across a wide variety of conditions. They have also been leaders in engaging patients and families in quality care and in recognizing physicians who facilitate others who improve care. ${ }^{14}$ Many specialties are developing procedural registries, including ophthalmology, surgery, and cardiology. Especially notable is the American Board of Cardiothoracic Surgery, whose national registry has driven dramatic improvement over a generation, and the American Board of Orthopedics, which has piloted assessing patientreported outcomes for specific procedures as a part of certification. Finally, the specialty of dermatology has identified care gaps in their specialty and developed an intervention combining key literature with quality improvement activities. This approach has been very popular with practicing dermatologists.

Family medicine has many options! We look forward to your ideas about what we should prioritize and how we should move forward. We will provide updates going forward.

\section{To see this article online, please go to: http://jabfm.org/content/ 34/2/455.full.}

\section{References}

1. National Research Council, Institute of Medicine. The National Academies collection: reports funded by National Institutes of Health. In: Woolf SH, Aron L, eds. U.S. health in international perspective: shorter lives, poorer health. Washington, DC: National Academies Press; 2013.
2. Woolf SH, Schoomaker H. Life expectancy and mortality rates in the United States, 1959-2017. JAMA 2019;322:1996-2016.

3. Institute of Medicine. Crossing the quality chasm: a new health system for the 21 st century. Washington, DC: National Academies Press; 2001.

4. McGlynn EA, Asch SM, Adams J, Keesey, et al. Quality of health care delivered to adults in the United States. N Engl J Med 2003;348:2635-45.

5. Institute of Medicine. To err is human: building a safer health system. Washington, DC: National Academies Press; 1999.

6. MCGlynn EA. Measuring and improving quality in the US: where are we today? J Am Board Fam Med 2020;33:S28-S35.

7. Dzau VJ, Shine KI. Two decades since To Err Is Human: progress, but still a "chasm." JAMA 2020; 324:2489-90.

8. Bodenheimer T, Sinsky C. From Triple to Quadruple Aim: care of the patient requires care of the provider. Ann Fam Med 2014;12:573-6.

9. Cruess SR, Cruess RL. Professionalism, communities of practice, and medicine's social contract. J Am Board Fam Med 2020;33:S50-S56.

10. Newton W, Peterson L, Morgan ZJ, et al. Rebuilding after COVID: planning systems of care for the future.J Am Board Fam Med 2020;33: 485-8.

11. Goodreads. Available from: https://www.goodreads. com/author/quotes/285217.Johann_Wolfgang_von_ Goethe. Accessed January 19, 2021.

12. PRIME Registry: Improving America's Health. 2021. Available from: https://primeregistry.org/. Accessed July 28, 2020.

13. Shuemaker JC, Phillips RL, Newton WP. Clinical quality measures in a post-pandemic world: measuring what matters in family medicine. Ann Fam Med 2020;18:380-2.

14. Lannon C, Nichols DG. The role of certifying boards in improving health: the example of the American Board of Pediatrics. J Am Board Fam Med 2020;33:S36-S41. 